\title{
Membrana amniótica e pericárdio canino como curativos biológicos na preparação do leito receptor para enxertia cutânea autógena
}

\author{
[Canine amniotic membrane and pericardium as a biological wound dressing in the preparation of the \\ recipient site to autogenous skin graft] \\ M.L. Aceto ${ }^{1}$, M.C.O.C. Coelho ${ }^{2 *}$, V.L.C. Monteiro ${ }^{3}$, A.M.A. Carneiro-Leão ${ }^{2}$, \\ M.M. Melo-Júnior ${ }^{4}$ \\ ${ }^{1}$ Médica veterinária autônoma - Recife, PE \\ ${ }^{2}$ Universidade Federal Rural de Pernambuco \\ Rua Dom Manoel de Medeiros, s/n - Dois Irmãos \\ 52171-900 - Recife,PE \\ ${ }^{3}$ Aluna de pós-graduação - UFRPE - Recife, PE \\ ${ }^{4}$ Aluno de pós-graduação - CCS-UFPE - Recife, PE
}

\begin{abstract}
RESUMO
Avaliou-se o tecido de granulação formado com o uso de membrana amniótica e pericárdio canino como curativo biológico oclusivo em feridas cutâneas experimentais. Utilizaram-se 15 cães; em cada animal, foram produzidas três feridas na região torácica dorsal. As feridas craniais e caudais receberam aloenxerto de membrana amniótica e pericárdio canino, respectivamente, e as feridas intermediárias (controle) curativo não aderente. No sétimo dia, sobre todas as feridas, foram feitas auto-enxertias cutâneas. Foram realizadas avaliações clínicas, histológicas, incluindo contagem e diâmetro médio dos vasos sangüíneos do tecido de granulação bem como coleta de secreção das feridas e dos enxertos. Concluiu-se que a aplicação do curativo de membrana amniótica e de pericárdio canino sobre feridas cutâneas durante sete dias não estimula o aparecimento da granulação necessária para a aplicação à enxertia cutânea, podendo, apenas, ser utilizado como curativo biológico oclusivo.
\end{abstract}

Palavras-chave: cão, enxerto, membrana amniótica, pericárdio, tecido de granulação

\begin{abstract}
The granulation tissue formed with the use of amniotic membrane (ME) and canine pericardium (PE) as an occlusive biological dressing in experimental cutaneous wounds was evaluated Fifteen dogs, having three wounds on the dorsal thoracic region of each (FA -amniotic, FC -control and FP-pericardium) were used. Clinical and histological evaluations were carried out, including counting and measuring the average diameter of the blood vessels of the granulation tissue, as well as bacteriological exams (swabs) of the wounds and the grafts. The granulation tissue formed after seven days of using the canine amniotic membrane showed a vascular histological aspect, being able to be favorable to the cutaneous grafting. It was concluded that the use of amniotic membrane and canine pericardium dressing on cutaneous wounds during seven days did not stimulate the presence of granulation necessary for the use of cutaneous grafting, however, it can be used as an occlusive biological graft.
\end{abstract}

Keywords: graft; amniotic membrane; pericardium; granulation tissue; dogs

Recebido em 21 de maio de 2004

Aceito em 18 de dezembro de 2006

*Autor para correspondência (corresponding author)

E-mail:dmv@ufrpe.br 


\section{INTRODUÇÃO}

A cicatrização, como fenômeno biológico, exige a participação ativa de células e um ambiente local favorável para o metabolismo celular. Nas feridas cutâneas, esse ambiente deve ser oferecido, aplicando-se curativos, e os princípios gerais de cuidado com as feridas, como umidade, limpeza e cobertura, devem ser respeitados (Coelho, 1998).

Os substitutos temporários de pele são classificados, de acordo com sua origem, em biológicos (aloenxerto, xenoenxerto e derivados de tecidos), sintéticos e compostos ou biossintéticos (Pitanguy et al., 1988; Dockhorn et al., 1992) e são indicados no tratamento de feridas limpas e com pouca exsudação.

Membranas biológicas, como pericárdio e amniótica, têm sido empregadas com essa finalidade, conforme sugerido por Bellenzeni et al. (1998). Oliveira e Alvarenga (1998) afirmaram que as membranas biológicas contribuem para o processo de cicatrização por protegerem mecanicamente a ferida, prevenirem a infecção e estimularem a neovascularização local.

O resultado da enxertia depende exclusivamente do tipo de enxerto, da área doadora, do preparo rigoroso do leito receptor e da ausência de movimentos pós-operatórios entre o enxerto e o leito receptor (Dockhorn et al., 1992; Anderson, 1997).

Um leito receptor com bom suprimento sangüíneo viabiliza a integração do enxerto, sendo que tanto feridas cirúrgicas recentes como feridas com tecido de granulação rosado, saudável, livre de infecções e corpos estranhos, são adequadas à enxertia (Pavletic, 1996; Pope, 1996). Outros critérios para a integração do enxerto incluem a altura do tecido de granulação em relação às margens da pele adjacente e o controle da hemorragia do leito receptor, prevenindo a formação de hematomas e seromas (Fox e Probst, 1982).

Este trabalho teve o objetivo de avaliar o tecido de granulação formado abaixo dos curativos biológicos (membrana amniótica e pericárdio canino), em feridas experimentais em cães, até o sétimo dia de pós-operatório e adequar o leito receptor à enxertia cutânea autógena.

\section{MATERIAL E MÉTODOS}

Foram utilizados 15 cães, machos e fêmeas, SRD e clinicamente sadios, provenientes do canil municipal da vigilância ambiental. Os animais permaneceram por um período de adaptação de 15 dias, no qual foram avaliados quanto à higidez orgânica, por meio de observação clínica, hemograma e exame coproparasitológico. Em cada cão, foram produzidas três feridas na linha dorsal torácica, retirando-se um fragmento de $4 \mathrm{~cm}^{2}$ de pele total, previamente demarcado com molde de papel adesivo estéril. As feridas craniais de todos os cães formaram o grupo FA (membrana amniótica); as feridas intermediárias, o grupo FC (controle); e as feridas caudais, o grupo FP (pericárdio).

As feridas dos grupos FA e FP receberam aloenxerto de membrana amniótica e pericárdio canino, respectivamente. Essas membranas foram retiradas do meio de conservação (glicerol a 98\%), hidratadas por 30 minutos em solução de $\mathrm{NaCl}$ 0,9\%, recortadas e aplicadas sobre a ferida. Suas bordas estenderam-se cerca de $1,5 \mathrm{~cm}$ das margens da ferida e foram fixadas à pele íntegra com cola de cianoacrilato ${ }^{1}$. A membrana amniótica manteve um contato estreito com o leito da ferida, sendo aplicado um curativo compressivo com gaze esterilizada. As feridas do grupo $\mathrm{FC}$ receberam um curativo não aderente $^{2}$ de viscose, impregnado com uma emulsão neutra, aplicado sobre a ferida, colado à pele íntegra e, então, coberto com um curativo de gaze esterilizada. As feridas foram observadas diariamente, e os curativos de gaze foram trocados a cada 24 horas, em todos os grupos. O período pós-operatório se completou sete dias após o transcirúrgico.

Para avaliações bacteriológicas, foram realizadas coletas de tecido de granulação no sétimo dia do pós-operatório. As amostras de tecido foram semeadas em ágar-sangue de ovino a $8 \%$ e incubadas a $37^{\circ} \mathrm{C}$ por 24 e 48 horas. Os crescimentos bacterianos foram classificados por

${ }^{1}$ Super Bonde - Henkel Loctite Adesivos Ltda. São Paulo-SP. ${ }^{2}$ Adaptic - Johnson. Texas-USA 
meio de provas bioquímicas e morfotintoriais pelo método de Gram (Carter, 1988).

Avaliação histológica foi realizada em todas as feridas no sétimo dia de pós-operatório, utilizando-se um fragmento retirado da junção entre o tecido de granulação e a pele íntegra. Os fragmentos foram fixados em solução tamponada de formaldeído $10 \%$, processados para inclusão em parafina, cortados em micrótomo $(4 \mu \mathrm{m})$, corados pelo método da hematoxilina-eosina e tricrômico de Masson e examinados sob microscopia óptica.

As enxertias cutâneas foram realizadas no sétimo dia sobre os leitos de granulação das feridas previamente produzidas. Iniciou-se, então, o debridamento do tecido de granulação com compressa de gaze e a resecção do tecido de granulação exuberante antes da enxertia. A área doadora do enxerto foi a face lateral do membro pélvico direito na região femoral e ao redor dos leitos receptores. O tórax de todos os animais foi envolvido por malha de algodão. Os animais foram avaliados clinicamente 24 horas após a aplicação do auto-enxerto e diariamente até o $10^{\circ}$ dia de pós-operatório. Todas as feridas enxertadas foram avaliadas histologicamente no $10^{\mathrm{o}}$ dia de pós-operatório, utilizando-se um fragmento retirado da junção entre a pele íntegra e a área enxertada, na margem lateral esquerda das feridas. As avaliações das feridas enxertadas foram realizadas no quinto e no $10^{\circ}$ dia após a enxertia; nessa, foram observados: aspectos de coloração, presença de edema, fragmentação, secreção, deiscência, enfisema, crosta, necrose e tecido cicatricial. A classificação da secreção foi feita seguindo três parâmetros: quantidade (ausente, leve e intensa), coloração (amarela, verde, marrom e vermelho) e aspecto (seroso, mucoso, purulento, mucopurulento e serosanguinolento). Quanto à intensidade de cor, as feridas foram classificadas em pálida, rosada, com hiperemia leve, moderada ou intensa.

Os resultados obtidos foram expressos como média \pm desvio-padrão, submetidos à análise de variância e ao teste Tukey, ao nível de significância de $\mathrm{P} \leq 0,05$ (Arango, 2001). O número médio de vasos no tecido de granulação de cada grupo estudado foi obtido pela contagem dos vasos sangüíneos presentes em cinco campos (200X) de todas as lâminas histológicas.

\section{RESULTADOS E DISCUSSÃO}

Não foi observado crescimento bacteriano ou fúngico nas membranas conservadas em glicerol 98\%. Foram isolados, ao sétimo dia de tratamento, Staphylococcus sp. e Streptococcus sp. nas feridas dos grupos FA e FP, e Micrococcus sp. nas feridas do FP.

No tecido de granulação, avaliado ao sétimo dia, observaram-se macrófagos e fibrócitos, além de sinais de resposta inflamatória aguda (infiltrado eosinofílico), em especial nas feridas-controle (FC), que também exibiram neovascularização e presença de fibras colágenas. Foi possível observar ainda que o uso de membrana amniótica estimulou uma resposta predominantemente vascular, ao passo que o pericárdio promoveu maior síntese de fibras colágenas. Esse aspecto representa um padrão predominantemente colágeno, sugerindo estádio posterior do processo de reparo, quando comparado ao controle e à membrana amniótica, embora essa última não tenha oferecido uma oclusão duradoura devido às fragmentações observadas durante o tratamento, interferindo positivamente no processo cicatricial, já que diferiu histologicamente das FC.

Quanto ao número médio de vasos, não houve diferença estatisticamente significativa entre as FC e FA, compatível com a análise qualitativa dos tecidos em questão. Entretanto, em FP houve redução significativa do número de vasos na ordem de $55 \%$ e $34 \%$, em relação à $\mathrm{FC}$ e $\mathrm{FA}$, respectivamente. Quanto ao diâmetro médio dos vasos sangüíneos, observaram-se reduções significativas em FA e FP na ordem de 48,4\% e $89,1 \%$, comparadas à $\mathrm{FC}$, respectivamente. Dessa forma, notou-se que as FP encontravam-se num estágio de cicatrização mais avançado que FA e FC, demonstrado pela diminuição do diâmetro dos vasos neoformados, presentes no tecido de granulação e pelo padrão colagenoso determinado na análise dos cortes histológicos desse tecido. Segundo Alison (1992), esses vasos regridem conforme haja deposição de fibras colágenas e transição à fase de maturação. Os resultados sugerem que a capacidade de oclusão, observada clinicamente com a aplicação do curativo de pericárdio canino, tenha favorecido, como descrito por Hilário e Vasques (1994), a síntese de colágeno e, conseqüentemente, a resolução do processo cicatricial. FA apresentou 
valores médios intermediários na contagem do número de vasos em relação à $\mathrm{FC}$ e $\mathrm{FP}$, mas não houve diferença significativa entre os valores de FA e FC. Entretanto, a avaliação qualitativa do tecido de granulação formado no grupo FA sugere um padrão vascular. Com relação ao diâmetro dos vasos, FA obteve também valores intermediários e significativamente diferentes de FC e FP. Embora as membranas amnióticas aplicadas não tenham oferecido uma oclusão duradoura devido às fragmentações observadas, essas membranas, quando aplicadas sobre feridas cutâneas, parecem interferir na progressão do processo cicatricial, já que diferiram histologicamente das FC.

No grupo FC, observou-se maior número médio de vasos sangüíneos, porém esse resultado não foi significantemente diferente do observado em FA. O tecido de granulação de FC caracterizouse por um padrão fibrovascular, intermediário à FA (vascular) e FP (colagenoso). O maior diâmetro dos vasos pode sugerir a evolução dos capilares para vênulas e arteríolas de maiores calibres, os quais posteriormente tiveram os diâmetros reduzidos e foram substituídos por tecido colagenoso (Oliveira e Alvarenga, 1998), como observado principalmente em FP.

Os resultados clínicos e bacteriológicos das FA não indicam o uso da membrana amniótica como curativo oclusivo não aderente, embora essa membrana parecesse interferir na atividade biológica do processo cicatricial. Estudos sobre as propriedades angiogênicas contidas nessa membrana, como os de Subrahmanyam (1995) e Oliveira e Alvarenga (1998), atribuíram à membrana amniótica humana uma propriedade angiogênica, com formação profusa de tecido de granulação estimulado por fatores de crescimento e angiogênicos presentes no âmnio, os quais devem ser considerados, pois, provavelmente, contribuem para uma rápida epitelização.

No quinto dia, após a enxertia cutânea, observouse secreção purulenta moderada a abundante em todas as feridas. No $10^{-}$dia, todas as feridas apresentaram menor quantidade de secreção, variando de leve a moderada. De acordo com Monteiro et al. (2001), a pele dos cães possui uma flora bacteriana residente e transitória. Como esses animais têm estreita relação com o solo, é provável que a pele entre em contato com fezes e outras impurezas, contaminando-se com microrganismos os quais, possivelmente, seriam os responsáveis pela presença de secreção purulenta.

Os grupos FA e FP apresentaram valores semelhantes de fragmentação dos enxertos, próximo de $30 \%$, tendo aspecto crostoso ou, às vezes, com lise parcial. A deiscência foi observada por ruptura da pele enxertada. No $10^{\circ}$ dia, todos os enxertos apresentavam necrose, e as feridas sob eles mostravam-se contraídas com uma pequena área de tecido de granulação. Embora não tenha havido a pega dos enxertos aos leitos de granulação, os fragmentos de pele agiram como curativos oclusivos, proporcionando a diminuição da exsudação com manutenção de umidade, a epitelização e a contração das feridas. Essas observações, também, foram feitas por Chanda et al. (1994), que utilizaram a pele como curativo em cobaios. As características de um curativo primário oclusivo foram descritas por Paulo (1997), Bellenzani et al. (1998) e Coelho (1998), os quais citaram que o ambiente úmido, associado aos fatores locais, acelera o movimento celular de reepitelização.

Observou-se, em todas as feridas, formação de tecido cicatricial caracterizado pela proliferação de fibroblastos, deposição e alinhamento das fibras colágenas, regressão dos infiltrados celulares inflamatórios (neutrófilos, eosinófilos e macrófagos) e de parte dos vasos sangüíneos neoformados do tecido de granulação, além de reepitelização do leito da ferida, como descrito por Alison (1992). Não foi possível observar diferenças quanto à reepitelização nas feridas estudadas.

$\mathrm{Na}$ histologia dos enxertos, observaram-se ausência de núcleos celulares, intensa eosinofilia e manutenção do arcabouço celular (cell outlines), sugerindo necrose coagulativa. A infecção, descrita principalmente em FP, provavelmente favoreceu a não integração dos enxertos e subseqüente necrose. Embora não tenha sido mensurada a quantidade de bactérias por grama de tecido, a presença de Streptococcus $\beta$-hemolítico inviabiliza a integração de um enxerto (Dockhorn et al., 1992) devido a um leito de granulação vascular escasso (Pavletic, 1996; Pope, 1996; Anderson, 1997). 


\section{CONCLUSÕES}

O curativo de membrana amniótica e pericárdio canino sobre feridas cutâneas durante sete dias não estimula $\mathrm{o}$ aparecimento da granulação necessária para a aplicação à enxertia cutânea, porém pode ser utilizado como curativo biológico oclusivo.

\section{REFERÊNCIAS BIBLIOGRÁFICAS}

ALISON, M.R. Repair and regenerative responses. In: McGEE, J.T.; ISAACSON, P.G.; WRIGHT, N.A. (Eds). Oxford text book of pathology. Oxford: University Press, 1992. v.1, p. $365-388$

ANDERSON, D. Practical approach to reconstruction of wounds in small animal practice- Part 1. Comp. Anim. Pract., v.19, p.501-510, 1997.

ARANGO, G.H. Testes paramétricos. In: ARANGO, G.H. Bioestatística teórica e computacional. Rio de Janeiro: Guanabara Koogan, 2001.

BELLENZANI, M.C.R.; MATERA, J.M.; GIACÓIA, M.R. Homologous pericardium as a biological dressing for treatment of distal limb wound in horses- experimental study. Acta Cir. Bras., v.13, p.238-242, 1998.

CARTER, G.R. Fundamentos de bacteriologia e micologia Veterinária. São Paulo: Roca, 1988. 249 p.

CHANDA, J.; MOHANTY, R.M.; MURALEEDHARAN, C.V. et al. Use of glutaraldehyde - gentamicin - treated bovine pericardium as a wound dressing. Biomaterials, v.15, p.68-70, 1994.

COELHO, M.C.O.C. Substitutos temporários de pele no processo cicatricial de falhas cutâneas: estudo experimental em cães (Canis familiaris), 1998. 102f. Tese (Doutorado em Ciência Animal) - Escola de Veterinária, Universidade Federal de Minas Gerais, Belo Horizonte.
DOCKHORN, L.F.; ZANINI, S.A.; MELEGA, J.M. Enxertos de pele. In: MELEGA, J.M.; ZANINI, S.A.; PSILLAKIS, J.M. Cirurgia plástica reparadora e estética. 2.ed. São Paulo: Medsi, 1992. p.35-42.

FOX, S.M.; PROBST, C.W. Split-thickness autogenous skin transplantation in a dog. Vet. Med. Small Anim. Clin., v.98, p.782-787, 1982.

HILÁRIO, A.H.; VASQUEZ, L.A.M. Utilização de um substituto temporário de pele nas perdas cutâneas de pacientes ambulatoriais. Rev. Bras. Cir., v.78, p.393-398, 1994.

MONTEIRO, V.L.C.; COELHO, M.C.O.; CARRAZZONI, P.G. et al. Antissepsia de pele de cães utilizando-se chlorhexidina a $2 \%$, povidine a $10 \%$ e álcool iodado a $5 \%$. Cienc. Anim., v.11, p.7-12, 2001.

OLIVEIRA, V.A.; ALVARENGA, J. Membrana amniótica preservada em glicerina no reparo de feridas cutâneas de membros locomotores de eqüinos. Cienc. Rural, v.28, p.623-628, 1998.

PAULO, N.M. Estudo comparativo entre membrana amniótica de eqüino preservada em glicerina a $98 \%$ e em ácido acético glacial a $0,25 \%$ no tratamento de feridas cutâneas experimentais no cão. 1997. 64f. Tese (Doutorado) - Faculdade de Medicina Veterinária e Zootecnia, Universidade de São Paulo, São Paulo.

PAVLETIC, M.M. Técnicas de enxertadura cutânea. In: BOJRAB, M.J. Técnicas atuais em cirurgia de pequenos animais. São Paulo: Roca, 1996. p.431-447.

PITANGUY, I. Utilização de película de celulose (biofill $^{\circledR}$ ) como curativo biológico. Rev. Bras. Cir., v.78, p.317-326, 1988.

POPE, E.R. Enxertamento cutâneo em malha. In: BOJRAB, M.J. Técnicas atuais em cirurgia veterinária de pequenos animais. 3.ed. São Paulo: Roca, 1996. p.447-452.

SUBRAHMANYAM, M. Amniotic membrane as a cover for micro skin graft. $B r . J$. Plast. Surg., v.48, p.477-478, 1995. 